\title{
Apresentação do Dossiê: \\ História e Gênero na América Latina: problemas, possibilidades e desafios interpretativos (séculos XIX e XX)
}

Júlia Glaciela da Silva Oliveira ${ }^{1}$

Valeria Silvina Pita ${ }^{2}$

Nos últimos anos, a América Latina foi atravessada por uma nova "onda" feminista que reanimou tanto antigas pautas do movimento como experiências novas. Em 2015, teve início a marcha Ni una a Menos, coordenada pelo coletivo feminista argentino de mesmo nome, trazendo para a cena pública as denúncias sobre as várias faces da violência de gênero, entre elas o feminicídio. Dois anos depois, as feministas convocaram uma greve geral com um programa que visava denunciar a precarização das relações de trabalho, a falta de reconhecimento das tarefas domésticas e do cuidado materno, as longas jornadas de trabalho, o desemprego e o crescente endividamento. Toda essa efervescência foi marcada por iniciativas legislativas e intervenções que ocuparam espaços públicos, constituindo uma experiência massiva e heterogênea que conectou as ruas com a academia e os centros de pesquisa. Tais ações resultaram em uma série de protestos e marchas que se estenderam por cidades do Brasil, Chile, México, Peru e Uruguai. Em 2018, acompanhamos os pañuelos verdes, utilizados pelas ativistas argentinas em uma clara referência às Madres de Mayo, que se tornaram símbolo da luta pelos direitos reprodutivos na América Latina. No Chile, em outubro de 2019, irrompeu uma série de ações organizadas por diferentes movimentos sociais, como estudantes, idosos,

\footnotetext{
${ }^{1}$ Doutora em História Social pela Universidade de São Paulo (USP0, é professora do Instituto Federal do Paraná (IFPR) e co-coordenadora do Grupo de Pesquisa em Gênero e História (GRUPEG-Hist). E-mail: julia.gsoliveira@gmail.com ORCID: https://orcid.org/0000-0002-9996-2343

${ }^{2}$ Doutora em História, é professora da Universidade de Buenos Aires (UBA) e pesquisadora do Instituto Interdisciplinario de Estudios de Género (FyL-UBA). E-mail: vspita@gmail.com
} 
trabalhadores, etc., contra as ações do presidente Sebastián Piñera, expondo, ainda, os efeitos do neoliberalismo no país. Adotado durante o regime militar de Augusto Pinochet, o modelo econômico diminuiu a responsabilidade do Estado em assuntos essenciais como saúde, educação, saúde e previdência social. As mulheres foram peças fundamentais nas ações ocorridas no país e, em novembro, organizaram a performance "Un violador en tu camino", que incluía canção com letra que denuncia a conivência de vários setores da sociedade, sobretudo do Estado, para com a perpetuação da violência sexual contra as mulheres. A performance ecoou em vários países da América Latina, Europa e Ásia e diversas mulheres foram às ruas, com vendas nos olhos, denunciar a violência de gênero em seus países ${ }^{3}$.

Estas ações apontam para uma transnacionalização das ações dos feminismos latinoamericanos, que têm demonstrado a importância de trazer a público, de forma conjunta e coordenada, pautas que são comuns às mulheres da região. Notoriamente, estes temas não são novos para os feminismos da América Latina e fazem parte das agendas desde os anos de 1960 e 1970. Na América Latina, esse período foi marcado por golpes militares que resultaram em regimes autoritários em países como Argentina, Bolívia, Brasil, Chile, Paraguai e Uruguai. Logo, as mulheres neste período estiveram engajadas de diferentes formas à resistência aos regimes militares, sendo que, para muitas, foi durante este processo que se descobriram feministas ou passaram a atuar em organizações feministas. Assim, sobretudo no Cone Sul, a experiência da luta pela redemocratização foi algo comum às latino-americanas. Mas, não apenas isso. As discussões sobre prazer sexual, maternidade, divisão social do trabalho, direitos reprodutivos e participação política foram partilhadas por muitas das ativistas latinoamericanas. Nos anos de 1980, quando dos primeiros Encontros Feministas Latino-Americanos e Caribenhos, a palavra autonomia era representativa dos vários desejos que alimentavam os discursos dos feminismos latino-americanos: independência das opiniões dos partidos políticos

\footnotetext{
${ }^{3}$ Em alguns destes países é notório o efeito destas manifestações. Em 2020, assistimos à descriminalização do aborto na Argentina, um fato inédito que se repetiu, em 2021, no México. Foi também neste ano que a Argentina protagonizou uma grande conquista ao reconhecer o cuidado materno como trabalho. Este fato permite às mulheres acrescentar de um a três anos de serviço ao tempo de contribuição da previdência, impactando diretamente na desigualdade de gênero resultante da divisão social do trabalho. O Chile aprovou, também em 2021, o projeto de lei que permite o casamento homoafetivo e a adoção de crianças por casais do mesmo sexo ou gênero.
} 
sobre as demandas femininas; das interferências dos discursos religiosos sobre a sexualidade e o desejo feminino; do Estado sobre a regulamentação dos corpo s. Isto é, decidir sobre o próprio corpo, a sexualidade, o trabalho e a maternidade. Além destes, os feminismos romperam com o silêncio em torno das várias faces da violência de gênero, sobretudo aquela que ocorria no espaço "sagrado" das famílias. Assim, os feminismos destas décadas provocaram um grande impacto em nossa contemporaneidade, discutindo temas considerados privados e tabus, como sexualidade, violência e família.

A eclosão dos feminismos na Europa, Estados Unidos e América Latina, durante os anos de 1960 e 1970, também reverberou na produção científica. Louise Tilly, historiadora norteamericana, em seu artigo “Gênero, história das mulheres e história social”, publicado em 1994, reflete sobre como a constituição do campo de estudos da História das Mulheres é tributário da efervescência do feminismo no período. A historiadora advoga que apesar de toda história ser herdeira de um contexto político, o campo da História das Mulheres tem um laço mais estreito com os projetos de transformação vigentes no período. Deste modo, a historiografia foi renovada com fontes e pesquisas que iluminavam a presença e agência de mulheres no passado. No entanto, apesar desta importante renovação, a História das Mulheres recebeu algumas críticas, sobretudo por não questionar as narrativas essencialistas e homogêneas a respeito do papel feminino. Neste mesmo contexto, diferentes grupos feministas questionavam o que era mulher e qual seria a bandeira do feminismo, uma vez que as experiências eram perpassadas por distintas clivagens, como as de raça, classe e sexualidade. Essas discussões motivaram a ramificação de diferentes grupos identitários como os feminismos negros, lésbicos e trans - que, para além das interrogações ao feminismo "geral”, também trazia indagações aos movimentos negro e homossexual.

Essas interrogações não passaram ao largo das preocupações teórico-metodológicas. Não por acaso, foi na década de 1980 que o conceito de gênero passou a compor as pesquisas acadêmicas e os discursos feministas ganharam força e abrangência na década de 1990. Em 1986, a historiadora norte-americana Joan W. Scott, publicou o artigo "Gender: a useful category of historical analysis", que se tornou uma referência central para os estudos de gênero e renovou, uma vez mais, a historiografia. Dialogando com os pressupostos do filósofo Michel Foucault a respeito da sexualidade, Scott questionará o determinismo biológico, indicando a 
necessidade de se pensar de forma relacional as definições de feminilidade e, logo, de masculinidade ao longo do tempo. Deste modo, assevera que ao realizar uma análise de gênero, deveriam perguntar como as assimetrias de gênero foram legitimadas e asseguradas e de que maneira a história participava destas. Neste artigo, a historiadora também já sinalizava preocupação com os usos que o conceito poderia adquirir, a exemplo de pesquisas que poderiam, simplesmente, substituir o termo "mulher" por "gênero"4.

Fato é que o conceito de gênero impactou fortemente o campo da História e abriu para pensar em sujeitos, grupos e questões que, até então, não eram vislumbrados pela historiografia. Seu caráter provisório e circunscrito à descrição situada, para evitar sua dimensão normativa, destaca diferenças e contingências em torno das identidades, dos posicionamentos e das experiências sociais. Prestar atenção ao movimento do tempo também possibilitou outras leituras e discussões. Por meio de novas fontes e perguntas, as análises de gênero passaram a pesquisas de diferentes áreas, a exemplo da História Social e Social do Trabalho, a História Política e a Cultural e a História das Arte. Tratando-se da América Latina, os estudos de gênero vieram acompanhados da necessidade de se pensar a constituição dos sujeitos e suas relações políticas e sociais de forma interseccional e de se refletir, especialmente, sobre as especificidades. Assim, esse dossiê buscou, ao articular História e Gênero no âmbito latinoamericano, lançar um desafio e um convite a fim de reunir diferentes tradições acadêmicas, historiográficas e metodológicas. Mas, também, convidar a rompermos com o nacionalismo metodológico que, muitas vezes, impera em nossas instituições e, assim, construirmos uma perspectiva mais ampla sobre as produções historiográficas realizadas em gênero na América Latina. Neste sentido, este dossiê conta com quinze artigos que trazem, por meio de fontes diversas, importantes questões sobre gênero, sexualidade e interseccionalidade para a historiografia latino-americana.

\footnotetext{
4 Posteriormente, em Usos e abusos do conceito de gênero, publicado em 2012, Scott trata, justamente, das disputas, sobretudo no campo político, em torno do conceito e de seu esvaziamento. A exemplo, assistimos a um aumento vertiginoso de grupos religiosos conservadores, na América Latina, que encamparam o intitulado discurso "anti-gênero" - sem compreensão do conceito - defendendo projetos refratários aos direitos das populações LGBTQI+ e aos Direitos Humanos.
} 
A seção se inicia com dois artigos que abordam a capital argentina, Buenos Aires, na segunda metade do século XIX. Em um período de transição política que envolvia disputas entre unitários e federalistas, vemos como as questões de gênero traziam clivagens diferentes para mulheres da elite e das camadas populares. Deise Cristina Schell, em "Baje usted la voz en sus discursos y en sus escritos": Juana Paula Manso e as tentativas de silenciar uma mulher pública na Argentina oitocentista", nos apresenta a trajetória da escritora, professora e jornalista, Juana Paula Manso, em Buenos Aires, na década de 1860. A intelectual teve uma atuação transnacional como jornalista e escritora no Brasil, Argentina e Uruguai e foi uma figura central para a imprensa feminista do Cone Sul. O trabalho de Schell, no entanto, concentra-se na produção da escritora em solo portenho e discute por meio da análise desta fonte e da troca de correspondência entre Manso e figuras políticas, a exemplo de Domingo Sarmiento, as várias tentativas de silenciamento que a intelectual enfrentou em Buenos Aires. Já “Modas, figurines y remiendos. Adquisición de vestuario y trabajo artesanal femenino en tiendas de modista. Ciudad de Buenos Aires, 1851-1869”, de Gabriela Mitidieri, por meio de um amplo corpus documental, analisa a participação feminina na produção de roupas, artigos e artefatos "à moda parisiense" e as relações de trabalho envoltas neste processo, como o papel das modistas na administração de lojas, de pequenas empresas comerciais e nas dinâmicas de aprendizagens. A autora traça um olhar crítico e interseccional sobre o cotidiano do trabalho e analisa como a moda participou da construção das clivagens sociais, uma vez que o uso de determinadas vestimentas e adereços traziam implicações sociais que endossaram e entrecruzaram questões de gênero, classe e raça.

Outro aporte à História Social do trabalho e sua interface com as relações de gênero é o artigo "La construcción sexual del oficio y la formación de la clase obrera tabacalera". El caso de las despalilladoras de La Habana en los albores de la época republicana, 1898-1902”, de Catalina del Mar Garrido Torres. Em um momento em que a sociedade cubana passava por uma transição política, deixando o status de colônia para o de república independente, a autora analisa a formação da classe operária tabacalera a partir das experiências das despalilladoras. A historiadora discute como a identidade da classe tabacalera foi forjada a partir de uma divisão sexual do trabalho, acentuando distinções de gênero, classe e raça. Para além destas questões, 
o artigo traz importantes reflexões sobre as mudanças e permanências no cotidiano de trabalho das classes populares após as lutas independentistas.

Já “Sometidas por la fuerza: El maltrato conyugal en el discurso teológico-jurídico del Puerto Rico del siglo XIX', de Cesar Augusto Salcedo Chirinos, aborda a agência das mulheres em Porto Rico. Trata-se de mulheres que denunciavam a 'mala vida' que levavam com seus maridos. Tomando como fonte autos criminais, o historiador demonstra que as denúncias, imbuídas de cenas de violência, eram apresentadas à autoridade secular que deveria dar início a um processo judicial eclesiástico. Caso o conflito não fosse resolvido entre os pares, poderia ser encaminhado para o Tribunal Eclesiástico para que fosse considerada a possibilidade de "separación de cama y techo", isto é, o divórcio. Como demonstra o autor, ainda que grande parte das mulheres não lograsse a separação, suas reivindicações demonstram o enfrentamento destas ao discurso teológico e jurídico, que defendia a submissão da esposa ao marido como manutenção da ordem social.

O dossiê também traz duas importantes análises sobre a escravidão nas Américas. Em "Para além das narrativas sobre concubinagem: gênero, escravidão e liberdade no Caribe francês (séculos XVIII e XIX)”, Letícia Canellas discute os estereótipos difundidos por meio de relatos de viajantes e missionários, segundo os quais as escravizadas conseguiam suas liberdades através das relações destas com homens brancos, em sua maioria "senhores", o que daria resultado a um processo de mestiçagem. A autora questiona esse argumento e aborda a experiência de mulheres escravizadas, na Martinica, nas Antilhas Francesas, na conquista de alforrias para si e suas famílias. Em sua análise, Canellas aponta para a necessidade de compreender o contexto em que tais relações ocorreram e como foram narradas, omitindo as condições de violência ou submissão às quais as mulheres afrodescendentes foram submetidas e que resultaram em um apagamento de suas estratégias e ações de sobrevivência e luta por liberdade. Carolina Passarini, por sua vez, em "Escravidão, abolição e gênero: mulheres negras, corpo e reprodução nas Américas” investiga como a manutenção da escravidão transatlântica foi construída sobre uma perspectiva. Centrada no princípio do partus sequitur ventrem, isto é, na hereditariedade materna, a autora aborda como o ventre feminino sustentou as relações escravistas nas colônias portuguesas, inglesas e espanholas, implicando, ainda, nos processos de abolição. 
Já o artigo "Mulheres intelectuais em trânsito na América Latina nos séculos XIX e XX: Maria Concepcion Gimeno Flaquer e Margaret Randall”, de Stella Gontijo e Cristiane Ribeiro, nos oferta uma análise centrada nos estudos transnacionais e feministas sobre a trajetória das intelectuais que decidiram deixar o Norte global para viver na América Latina. A espanhola, Concepcion Gimeno de Flaquer e a norte-americana Margaret Randall, viveram em períodos distintos, entre o fim do século XIX e meados do XX. Deste modo, por meio de uma análise centrada nos estudos feministas e transnacionais, as autoras buscam compreender como ambas as intelectuais romperam, negociaram ou pensaram os papéis de gênero de seus tempos e de que maneira contribuíram para a constituição de uma rede intelectual transnacional. Destacam que a produção resultante da experiência de ambas em território latino-americano teve um amplo impacto sobre a participação feminina, contribuindo para a inserção de outras mulheres no campo da produção intelectual.

O dossiê também recebeu um artigo que trata da virada do século XIX para o XX e, especialmente, do contexto da Belle Époque no Brasil e na Argentina. Tomando como fonte as revistas ilustradas em circulação em ambos os países, em "O (anti)feminismo nas representações da virilidade na imprensa ilustrada humorística (Brasil e Argentina, 19041918)”, Thaís Batista Rosa Moreira realiza uma análise sobre as representações de virilidade presente em ambas as publicações. De forma comparativa, a autora demonstra como as publicações recorriam à ironia, expressa por meio de chistes, charges e crônicas, para construir, a partir de uma visão sobre a virilidade, um discurso antifeminista que desqualificava ou distorcia os sentidos políticos do movimento. Para além das discussões sobre os discursos refratários aos feminismos, o artigo configura-se como uma contribuição aos estudos sobre as masculinidades.

A revolução Cubana, em 1959, foi um marco na história latino-americana e alimentou projetos e utopias em diferentes países entre os anos de 1960 e 1970, a exemplo da chegada ao poder da Unidade Popular no Chile, em 1970, pela via democrática. Por outro lado, a historiografia tem discutido como esses processos revolucionários trouxeram uma perspectiva conservadora em determinados campos e temas, a exemplo das questões de gênero e sexualidade. Neste aspecto, o dossiê conta com duas importantes contribuições, sendo a primeira o artigo A Velha Rosa no jardim da Revolução: tensões culturais, homossexualidade 
e autoritarismo em Cuba, de Jorge Luiz Teixeira Ribas. O autor toma como fonte o conto A Velha Rosa, do escritor e poeta Reinaldo Arenas, publicado em 1966. Por meio deste, discute como a personagem central, Rosa, enxerga a ruptura da velha Cuba, sobretudo em relação às mudanças no campo moral advindas com a revolução. Se as relações interraciais são suportadas no casamento entre sua filha com um homem negro, o mesmo não é válido para a homossexualidade do caçula. Deste modo, o artigo analisa como o governo revolucionário manteve uma visão conservadora no que tange à sexualidade e as relações homoafetivas, fortalecendo uma compreensão de masculinidade heteronormativa. Aline Fernanda Maciel, por sua vez, aborda como a opressão de gênero foi compreendida durante a transição política chilena, em 1970, durante o governo da Unidad Popular (UP). Em “(Re)pensando a Unidade Popular: Estado, Trabalho e Relações de Gênero na "vía chilena ao socialismo” (1970-1973), a historiadora se debruça, especialmente, sobre a tarefa de compreender as dinâmicas gendradas de trabalho nas fábricas têxteis, importante setor produtivo durante as tentativas de transição do capitalismo para o socialismo. Deste modo, a autora analisa qual o lugar ocupado pelas das demandas de gênero no programa de governo da UP e se este, em sua prática, rompeu ou reforçou padrões normativos de gênero relacionados, especialmente, às mulheres.

Como afirmado no início desta apresentação, os movimentos feministas, emergentes nos anos de 1960 e 1970 impactaram fortemente os campos da política, da arte e da cultura, bem como as pesquisas científicas que se dedicavam a analisar e pensar as demandas femininas. A própria categoria mulher, como exposto, foi interrogada a partir da pluralidade das experiências que não permitia falar das mulheres de forma homogênea e singular. Por esse caminho de reflexão, o artigo "Un encuentro liminal. Hacia la construcción regional de "la problemática de la mujer" (Buenos Aires, 1974)”, de Paula Lucía Aguilar faz uma análise genealógica do seminário "Perspectivas femininas na pesquisa social na América Latina", realizado em Buenos Aires, em 1974. Impulsionado por duas antropólogas estadunidenses, o evento reuniu pesquisadoras de diferentes campos do saber, dos Estados Unidos, Argentina, Brasil, Chile, Colômbia, República Dominicana, México, Panamá, Peru, Porto Rico e Venezuela a fim de discutir uma agenda em torno da “problemática da mulher”. Em sua análise, a autora destaca como esse evento, onde encontravam-se diversas pesquisadoras interessadas na "problemática da mulher na América Latina", foi fulcral na formação e consolidação de uma 
rede de pesquisadoras e núcleos de estudos de gênero e feminismo que tem, ao longo destes anos, discutido os problemas locais e regionais femininos, bem como pensado os desafios epistemológicos e teóricos que surgem ao se proporem a analisar esses problemas socioculturais. Deste modo, o artigo apresenta uma importante contribuição para compreendermos a constituição de uma rede transnacional, constituída por pesquisadores do norte e do sul, e os principais temas debatidos, bem como as ferramentas teóricas elaboradas neste intercurso.

Já o artigo “Teresinha Soares, Marta Minujín e Teresa Burga:conexões transnacionais sul-americanas sob a perspectiva de gênero" de Carolina Vieira Filippini Curi, nos apresenta como os feminismos também impactaram o fazer artístico. À luz dos estudos de gênero, a autora analisa a produção de três artistas latino-americanas, do Brasil, da Argentina e do Peru, associadas à pop arte, durante as décadas de 1960 e 1970. Em sua análise, para além de pensar as aproximações entre as três artistas, a historiadora discute como estas incorporam em suas obras temáticas relacionadas à problemática de gênero do período, a exemplo das questões sobre a sexualidade, corpo e desejo feminino. Assim, o artigo trata de um importante aporte aos estudos que entrecruzam gênero e arte.

Ainda pensando nos efeitos dos feminismos, agora nas searas teórico-metodológicas, Hariagi Borga Nunes faz um mapeamento das principais referências que compõem o denominado feminismo decolonial. Nas últimas décadas, a teoria decolonial tem suscitado reflexões, levantando importantes questões para a/os pesquisadores das Ciências Humanas, em especial a/os que se dedicam aos estudos de gênero e América Latina. Neste caminho, o artigo "Feminismos Descolonizadores: (lesbo)feminismo decolonial, las fronteras e enegrecendo o feminismo" confere um panorama sobre como as discussões de Yuderkys Espinosa Miñoso, Ochy Curiel, Maria Lugones, Silvia Cusicanqui, Gloria Anzaldúa, Sueli Carneiro e Lélia Gonzalez podem ofertar um caminho epistemológico para se pensar e se entrecruzar as questões de gênero, raça, classe e colonialidade.

Fechando o dossiê, temos dois artigos centrados no campo dos estudos de gênero e da História do Tempo Presente. Sob esse prisma, o artigo de Ana Laura Giorgi intitulado "Linda, inteligente, de buena familia, vos no deberías estar acá”: Dictadura y reconfiguración patriarcal en Uruguay", toma como fonte a literatura testemunhal e fontes orais, e, a partir das 
questões de gênero, discute a memória de ativistas políticas durante o período autoritário no Uruguai. Deste modo, a autora aborda, a partir dos estudos sobre a memória, os agenciamentos e, especialmente, as formas desobediência dessas mulheres frente ao autoritarismo do Estado. Por fim, Edméia Ribeiro, em "Gênero, discriminação e diversidade sexual em perspectiva política, no México (2012-2018)”, examina como as questões de gênero foram instrumentalizadas em documentos oficiais, programas, projetos, ações e leis do então presidente do México, Enrique Peña Neto, entre 2012 e 2018. Em um período em que o discurso "anti-gênero", promovido e difundido pela Igreja Católica ganhava espaço no país, a historiadora analisa de que maneira o presidente, na contramão, recorreu ao conceito de gênero, para construir uma imagem progressista para a sociedade. $\mathrm{O}$ artigo, assim, é uma importante contribuição para pensar como, em nossa atualidade, o conceito de gênero tem sido operacionado por diferentes forças políticas, alterando, continuamente, seu sentido.

Na seção de artigos livres, a revista apresenta a colaboração de Elvis Diana, que aborda a construção do mito da unidade nacional a partir da independência no Uruguai pela perspectiva da história intelectual, explorando os escritos do publicista Carlos María Ramírez, dos anos 1870-80. Estes escritos se remetem, num olhar retrospectivo, aos primeiros tempos de vida independente, evidenciando muito mais os traços de consenso político do que as tensões que marcaram, no Rio da Prata, o período da formação dos Estados nacionais, dominado pelo clima de guerras e tensões que opuseram as tendências à centralização e à fragmentação do poder. A releitura que o intelectual faz condiz com o processo de "invenção das tradições", mobilizado para gerar coesão em momento específico de busca pela pax política. $\mathrm{O}$ próximo artigo avança no tempo, abordando a primeira metade do século XX, mas o foco segue concentrado na história intelectual. O artigo das historiadoras Nathália Boaventura e Natally Dias aborda a produção do indigenista Manuel Gamio, concentrando-se em suas atividades como editor de revistas e como produtor de ações que colocavam em destaque o indigenismo mexicano no cenário latinoamericano.

Além das colaborações para o dossiê e para a seção artigos livres, o número traz um leque grande de resenhas. Quatro delas têm temáticas relacionadas ao próprio enfoque do dossiê, mostrando a efervescência da abordagem de gênero e história das mulheres em interface com a história latino-americana. A primeira delas, "Sobre o amor impaciente, a vida longa e as 
boas bruxas", trata do livro de Isabel Allende, escrito e publicado em 2020. Romilda Costa Motta nos apresenta, com muita leveza e olhar aguçado, como em Mulheres de minha vida a escritora afasta-se do romance e mergulha no gênero autobiográfico, ainda que sem abrir mão de personagens ficcionais, e, com capítulos curtos e doses de humor, constrói uma narrativa sobre sua aproximação com temas e ações do feminismo. Se a concepção de feminismo da autora pode ser vista de forma crítica, especialmente para as latino-americanas, a resenhista nos mostra como Allende surpreende ao discutir temas como sexualidade e prazer com os olhos na terceira idade.

No campo dos estudos de arte e gênero, Ana Beatriz Mauá nos apresenta "Feminismo y arte latino-americano: historia de artistas que emanciparan el cuerpo", da historiadora Andrea Giunta, lançado em 2018. Neste mesmo ano, junto com Cecilia Fajardo-Hill, a historiadora organizou a exposição "Mulheres radicais: arte latino-americana, 1960 a 1985”, que reuniu diversas obras de artistas latino-americanas atuantes a partir dos anos de 1960. A exposição trouxe importantes questões como o lugar da mulher no mundo da arte, a concepção de uma arte latino-americana e as categorias de "arte feminista" ou "arte feita por mulheres". A resenhista avalia que em sua obra, Giunta aprofunda as discussões presentes na exposição e apresenta ao público a trajetória de mulheres artistas, de diferentes regiões da América Latina, que utilizaram o corpo como meio de contestação às opressões de gênero. Nunes também observa que apesar de dialogar com importantes referências da crítica feminista de arte, a autora chama a atenção para as limitações de interpretações vindas da Europa e Estados Unidos para pensar as especificidades da arte e das artistas latino-americanas. Assim, Nunes considera que a obra oferece um importante aporte teórico-metodológico para pesquisas em História, Arte e Gênero na América Latina.

A resenha de Facundo Fernández Barrio, por sua vez, nos apresenta a coletânea Tramas Feministas al Sur, organizada pelas historiadoras argentinas Débora D’Antonio, Karin Grammatico e Catalina Trebisacce. A obra, publicada em 2021, pela editora Madreselva, questiona os "silêncios historiográficos" e propõe, por meio de um trabalho coletivo, pensar a partir das margens e do Sul. Assim, Barrio avalia que a obra apresenta um grande mosaico de temas, lançando luz sobre as experiências das trabalhadoras do sexo que recorreram ao feminismo abolicionista; às lutas dos movimentos lésbicos e transexuais para construírem 
espaços de memória; ao engajamento de artistas homossexuais afetados pelo HIV e passando por reflexões sobre o "estalido" chileno, de 2018. Assim, o resenhista avalia que a obra, por meio de uma perspectiva multidisciplinar, proporciona uma leitura que descortina experiências e memórias muitas vezes ignoradas.

Em “O que há de novo no front dos conservadores?", Eduardo dos Santos Chaves e Vitória Tiscoski Ramos apresentam as discussões presentes em "Gênero, neoconservadorismo e democracia: disputas e retrocessos na América Latina”. Organizado pela/os socióloga/os Flávia Biroli, Maria das Dores Campos Machado e Juan Marco Vaggione e publicado pela 2020 pela Editora Boitempo, a obra tem como contexto o avanço de regimes neoliberais e do conservadorismo religioso na região, a partir de 2010, momento em que muitos governos de esquerda chegaram ao fim por meio de eleições ou golpes. Segundo os resenhistas, a obra objetiva compreender quais são as novidades destes atuais ataques às agendas de igualdade de gênero e de que maneira estas posturas e atores conservadores reverberam nas democracias latino-americanas. Para isso, traça um panorama das alianças e estratégias que resultam no neoconservadorismo, termo utilizado para pensar os grupos religiosos contrários às temáticas relativas à igualdade de gênero. Em um momento em que se discute as possibilidades de rupturas das democracias latino-americanas, a obra traz instigantes reflexões sobre como os discursos conservadores se inovam e como instrumentalizam as temáticas de gênero.

O número traz ainda duas resenhas com temáticas não vinculadas ao dossiê. A primeira se volta para o momento da conquista, ao analisar o trabalho dos historiadores Luiz Estevam de Oliveira Fernandes e de Luis Guilherme Assis Kalil, intitulado 1519. Circulação, conquistas e conexões na Primeira Modernidade e lançado em 2021, pela Paco Editorial, de Jundiaí. Segundo a resenhista Hevelly Ferreira Acruche, o livro reúne ensaios de diferentes pesquisadores que discutem os múltiplos vieses do conceito de modernidade. Um sentido de orientação para trabalhos aí reunidos é a análise das condições em que, mediante a conquista, foram colocados diferentes personagens pertencentes às camadas populares. A abordagem, no entanto, ultrapassa o pressuposto da submissão per se, questionando a leitura rígida de que esses eram povos "vencidos" e sem agência histórica. Esta apreensão, segundo a autora, implica um olhar crítico ao eurocentrismo. 
A outra resenha, com a qual fechamos o número, é escrita pelo historiador argentino Omar Acha, professor da Universidade de Buenos Aires e pesquisador do Conicet. Em seus comentários, analisa o livro da historiadora argentina Claudia Touris, intitulado La constelación tercermundista. Catolicismo y cultura política en la Argentina, 1955-1976, publicado neste ano de 2021 pela Biblios, de Buenos Aires. Ao apresentar os problemas de pesquisa, referenciais teóricos e hipóteses do trabalho, a resenha explora a forma como a autora do livro abordou o catolicismo da Argentina contemporânea, explorando uma verdadeira constelação de fatores sociais e políticos, ao mergulhar na história do Movimento de Sacerdotes para o Terceiro Mundo e revelar, sem incorrer em dicotomias, as relações de sociabilidades ali presentes.

O volume ora apresentado pela Revista Eletrônica da ANPHLAC é extremamente rico, seja pelos artigos do dossiê e das resenhas ligadas a gênero e história das mulheres, seja pelos artigos e resenhas de temáticas variadas. Conectados com o seu tempo, as colaborações trazem férteis discussões conceituais, historiográficas e dimensões inovadoras da pesquisa em história da América Latina.

A todas, todos e todes, uma excelente leitura! 